\title{
Stability Analysis of Power System using FACT Controller
}

\author{
Sandeep Kaur, Raja Singh Khela
}

\begin{abstract}
The Stability of power system is influenced by different elements such as harmonic distortion attributed to non-linear loads, like unregulated voltage and unstudy current because of sag and swell and switching capacity. One of the effective methods is to make use of an integrated circuit of active shunt and series power filters such as Unified power quality conditioner in short called as UPQC. Such instrument binds a active shunt power filter with a active series power filter in Sequential formation, to simultaneously make up for the regular supply of voltage and current or to remove voltage and current disturbances in a power allocation and networking system. In present article, a latest layout of Unified power quality conditioner in short called as UPQC has been presented, consisting of a electromechanical device such as Direct current to direct current converter and the storage device joined to the dirct current (DC) link of the UPQC to counter the voltage disturbances.
\end{abstract}

Keywords: Unified power quality conditioner (UPQC), active shunt and series active power filter, voltage interruption, $D C / D C$ converter.

\section{INTRODUCTION}

The electrical power instruments due to their instinctive nonlinearity withdraw harmonic and resultant power from the power supply. In threephase power supply system, this can result in variations and leads to unnecessary neutral currents which results in reducing the efficency of the electrical system.So the introduced harmonics, reactive power load, the variations and the unnecessary neutral currents result in poor circuit effectiveness and low power factor. Apart from above, the electrical system is subject to varying transient states such as voltagesag and current swell, blinks etc. [1]-[2].These transient states alter the system voltage at the power distribution levels. Excessive reactive or resultant power of the load would result in increasing the generating capacity of the power plants which would increase the transmission losses in the supply lines[3-5] .The Quality of power generally addresses questions such as maintenance of a stable voltage at the common coupling point (CCP) for different distribution of voltage stages regardless of voltage varying, keeping a power factor equal to one, obstructing the imbalanced voltage and imblanced current from going up from different distribution systems,

Revised Manuscript Received on February 05, 2020.

* Correspondence Author

Sandeep Kaur*, Research Scholar, I.K. Gujral Punjab Technical University, Jalandhar ,Punjab(India)

Dr. Raja Singh Khela, Director, Doaba College Of Engineering \& Technology, Punjab (India)

(C) The Authors. Published by Blue Eyes Intelligence Engineering and Sciences Publication (BEIESP). This is an open access article under the CC BY-NC-ND license (http://creativecommons.org/licenses/by-nc-nd/4.0/) reducing the current and voltage harmonics in the system. [6-7]. One of a kind differently designed device intended to improve the power quality is two simultaneously fully controlled Direct Current / Alternating Current converter devices. In present state, depending on the power control programe, the converters may have different compensating functions.The converters can work as series active power filters and active shunt power filters to make up for load current, harmonics and variation in voltage supply. For this scenario, the system of Unified power quality conditioner in short called as UPQC or Unified Power Quality Conditioning system in short called as UPQS .Custom power equipment is a better alternative for power quality related issues in the distribution electric system. Among these devices for improving the quality of energy available, the UPQC has a better ability to compensate for sagging / swell. Control methods have the most important role in any system based on power electronics. It is the controlling plan and determines the effectiveness of a power distribution electric system. The efficiency of an outstanding in UPQC rely on exclusively on its different control algorithms brought to use. UPQC controlling system procedure affects the voltage and current signals and therefore determines the on/off timings of the inverter switches, to get the desired results .This research paper presents a different arrangement with the UPQC consisting of the Direct Current to direct current converter and supercapacitors to compensate for the voltage variations. The working of this system was corroborated by simulation techniques with the help of MATLAB \SIMULINK system tools.

\section{POWER QUALITY ISSUES}

Power Quality is the degree to which the power supply approaches the ideal scenario of stable uninterrupted without distortion and without any kind of disturbances in power supply.Any power problem due to voltage fluctuation variable current or deviation in frequency leads to failue of power devices. The most common Power quality issues faced in day to day life are,

- Voltage sag (or dip)

- Current swell

- Long and very short Interruption

- Harmonic distortion

- Voltage fluctuation

- Voltage spike

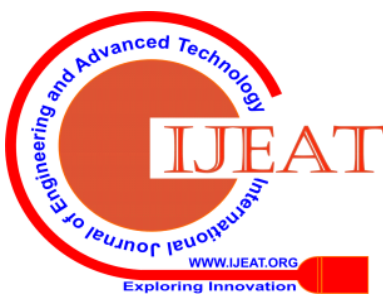




\section{BASIC ARRANGEMENT OF UPQC}

UPQC is the introduction of active shunt power filter and active series power filters, sequentially joinned on the direct current (dc) side, with a single DC capacitor common for both filters [8], as presented in Figure 1. In this UPQC, series part works for reducing the disturbances on supply side such as harmonics distortions, voltage imbalance, current swell, and voltage sag (dip). It introduces voltage in such proportion that it keeps the load voltage at a required level, in proportion and without fluctuation. The shunt section works for reducing the current quality issues faced by the user such as low power factor, current harmonics which are due to nonlinear load, load imbalance etc. It introduces current into the alternating current (AC) electric system in a way that the main current becomes maintained sinusoids and on equivalent phase with the main voltage. Generally three noteworthy controlling schemes for UPQC have been consume to bring the voltage sag(dip) in power system within control: 1) Actual power controlling scheme, by which an in phase voltage has been introduced with the help of a series inverter, called as UPQC-P. 2) Resultant power controlling scheme, by which a quadrature voltage is introduced, called as UPQC-Q and 3) a minimum Volt Amperes load scheme, because of that a series voltage is introduced at a paticular angle, called as volt Amperes (min). The volt Amperes load in UPQC-Volt Amperes (min) is found with help of voltage dip. In power distribution electric system, the voltage sag and current swell is major power quality related issue. In this research paper [9], the author has conceptualized power Quality problem of UPQC .

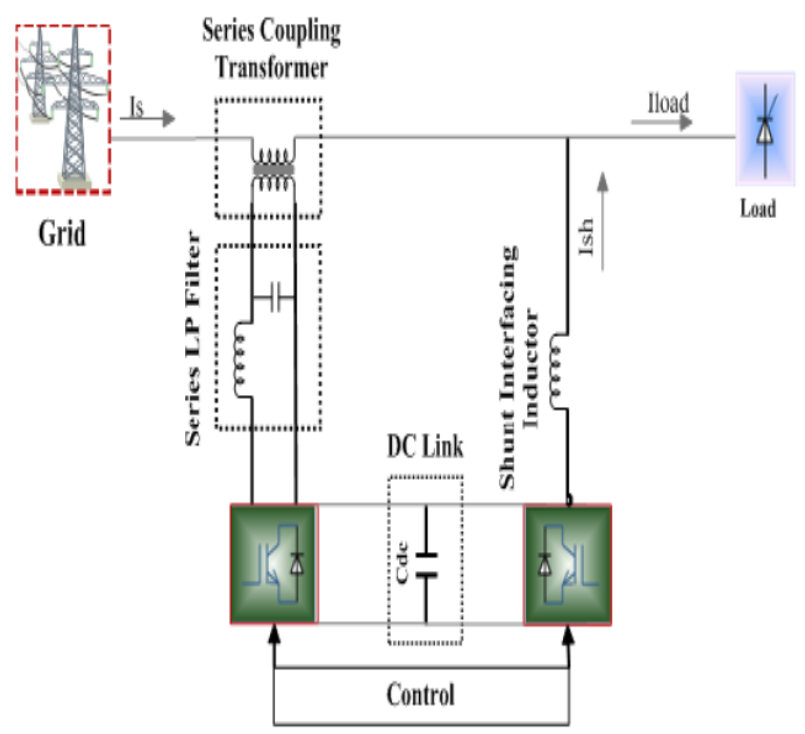

Figure 1 Block Diagram of Suggested UPQC

\section{SIMULINK CONCLUSIONS AND DELIBERATIONS}

The suggested system has been evaluated in Simulation by the use of sim power System BlockSet in MATLAB. Figure 2 shows the suggested UPQC. The electrical system is a classic three phase three wired system with a non-linear load which is characterized by the introduction of switching action and resulting current interruptions that is made up of a three phase rectifier which rectifies the input $\mathrm{AC}$ voltage by using three phase transformer and three diodes connected to each three phases of transformer with Resistances in series with capacitances (RC) load in the direct current (DC) side.

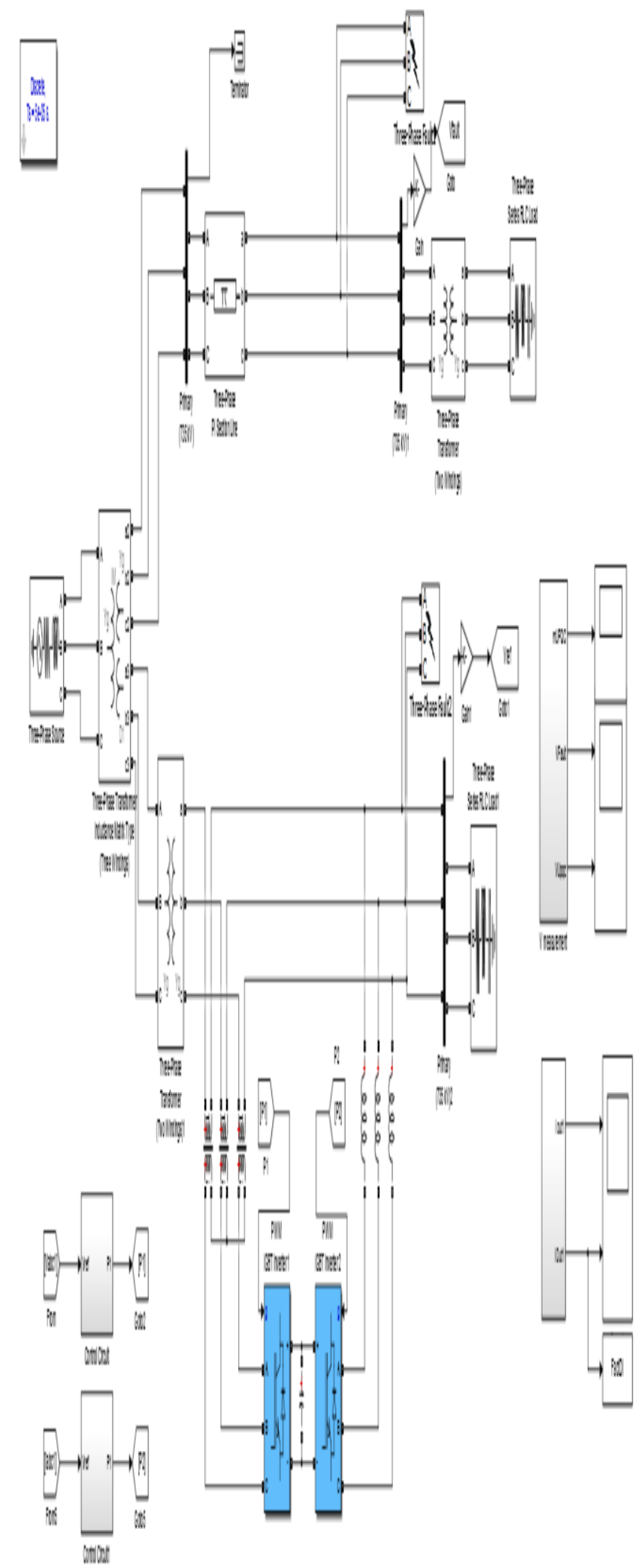

Figure 2 Simulink block diagram of suggested UPQC In this part, voltage sag has been introduced and the outcomes are analysed. The above figure 2 clearly shows how the UPQC series inverter has made changes in the load voltage as per the required objective. 


\section{UPQC SIMULATIONS AND RESULTS FOR VOLTAGE SAG}

The simulation results without UPQC for three-phase $11 \mathrm{kv}$ substation when fault occurs at load point and voltage decreases from $440 \mathrm{~V}$ to $357 \mathrm{~V}$ are shown below in figure 3.

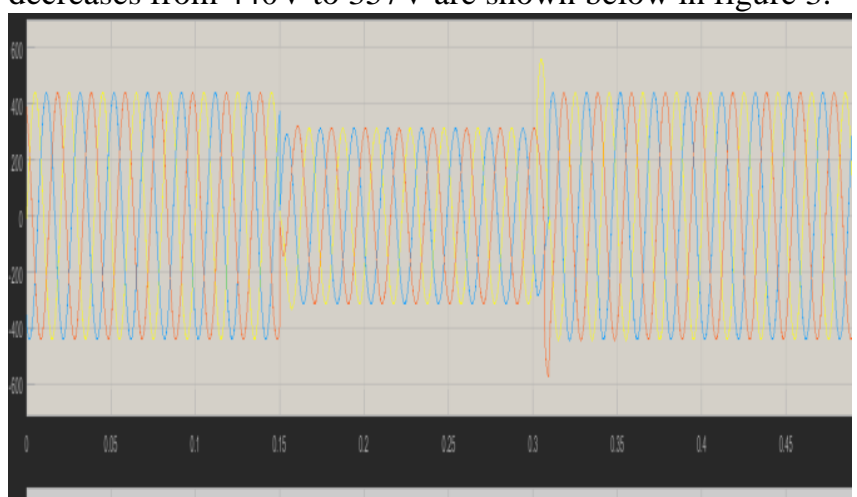

Figure 3.Simulation diagram for voltage with fault Simulation results with UPQC introduced at the three-phase $11 \mathrm{KV}$ Substation when fault occurs at the load point, then voltage which has reduced previously, again comes to the level of $435 \mathrm{~V}$. The results from figure 4 shows that by using UPQC the fault has been removed and the voltage figure comes to $435 \mathrm{~V}$.

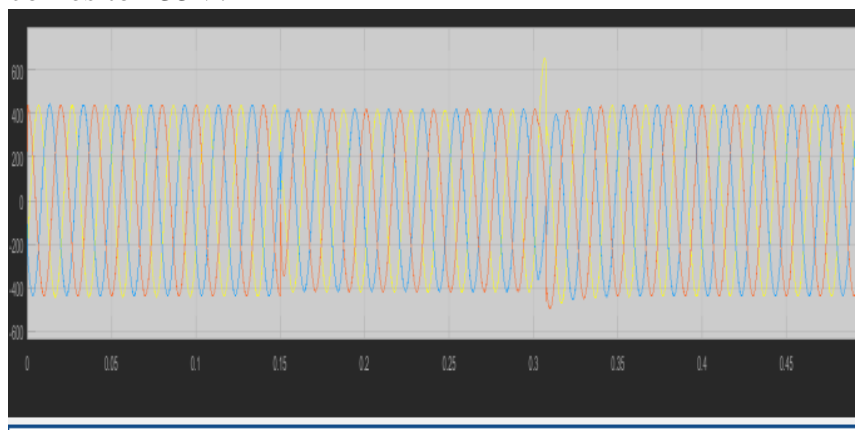

Figure 4.Simulation diagram for voltage with UPQC

\section{UPQC SIMULATIONS AND RESULTS FOR CURRENT SWELL}

The simulation results without UPQC for a three-phase $11 \mathrm{kv}$ substation when fault occur at load point then current increases from 45A to 62A as shown in figure 5.

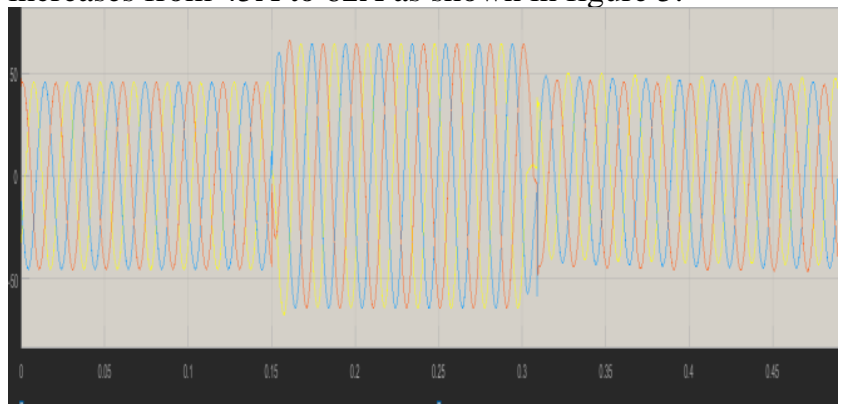

Figure 5. Simulation diagram for current with fault

Simulation results with UPQC introduced at the three-phase $11 \mathrm{KV}$ Substation when fault occurs at the load point, then current which has increased previously, again comes to the level of 48A. The results from figure 6 shows that by using UPQC the fault has been removed and the current figure comes to 48A.

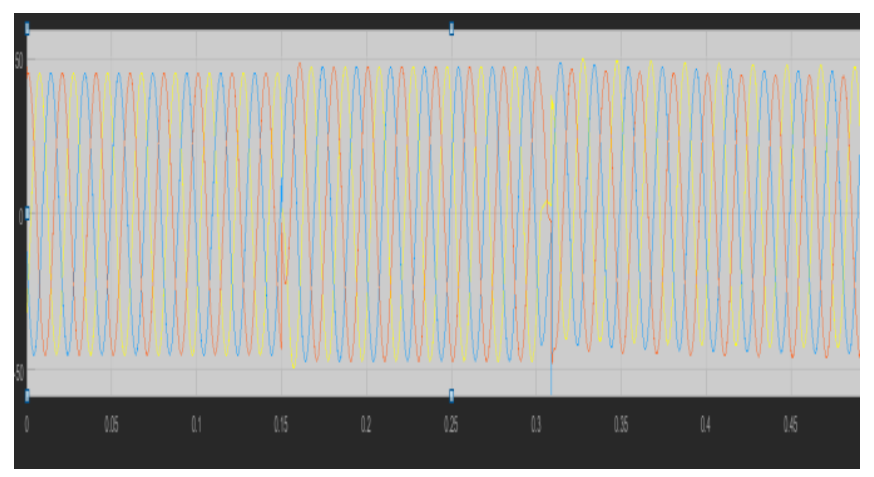

Figure 6.Simulation diagram for current with UPQC

\section{COMPARISON OF DESIGNED POWER SYSTEM VOLTAGE WITH THE REAL POWER SYSTEM VOLTAGE}

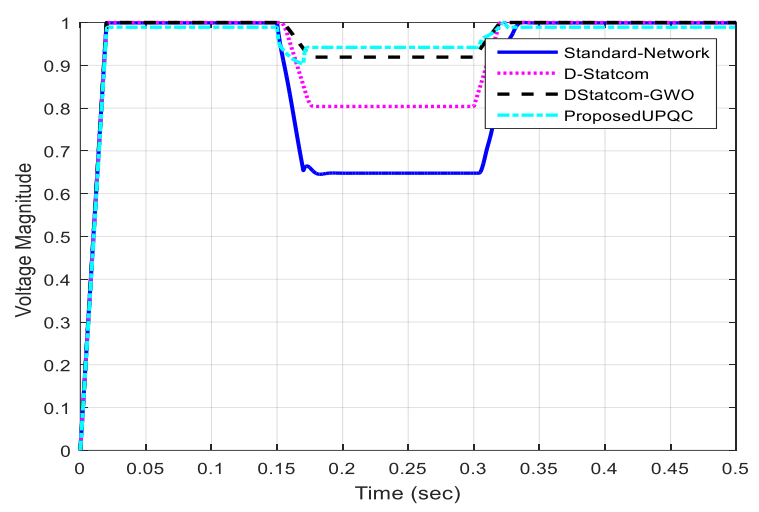

Figure 7.Comparison of voltage

Hence it is cleared from the graph that the voltage sag was 98 \% removed by using UPQC Fact controller.

\section{COMPARISON OF DESIGNED POWER SYSTEM CURRENT WITH THE REAL POWER SYSTEM CURRENT}

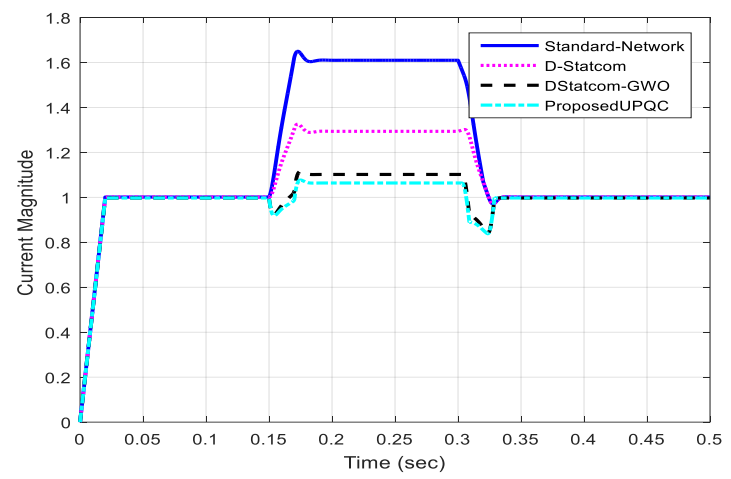

Figure 8.Comparison of current

Hence it is clear from the graph that the current swell has been $98 \%$ removed by using UPQC Fact controller.

\section{CONCLUSIONS}

In power distribution network, the power Quality is a serious problem. By going through available power devices, UPQC is one of the most productive devices for countering and addressing these burning problems.

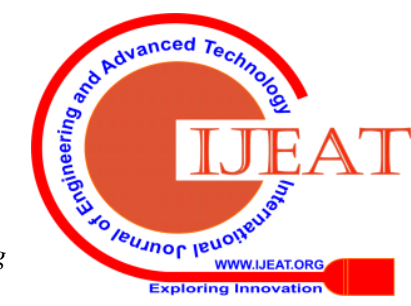


Through this research work a new technique of effective working of UPQC has been developed by the authors. Using the UPQC, the voltage sag (dip) and current swell problem has been addressed. The operation of new proposed system has been put to test through simulation operation with the help of SIMULINK in MATLAB. The suggested Unified power quality conditioner in short called as UPQC has the ensuing ability of enhancing the quality of power in current distribution system at the installation point .This paper presents a review on custom power devices, study of UPQC and control techniques which have been used to enhance the power quality.

\section{ACKNOWLEDGMENT}

Firstly Author would be pleased to offer her heartfelt sense of indebtedness to her guide and Mentor, Dr. Raja Singh Khela for the Guidance and support during the study of one of the objective of the Ph.D work. The guide's motivation was helpful for the author during her research work and composition of this paper, the authors would also be delighted to acknowledge the support provided by the distinguished and framed member of the Department of Research and Innovation, I.K. Gujral Punjab Technical University (IKGPTU), Kapurthala, Jalandhar, Punjab.

\section{REFERENCES}

1. L.H.Tey,P.L.So and Y.C.Chu,Unified power QualityConditionar for improveing power Quality Using ANN withHysterisis Control, IEEE Tran. Power Electronics, vol. 9,no.3, May 1994, pp. 1441-1446.

2. Hirofumi Akagi, Trends in Active Power Line Conditioners,IEEE Tran. Power Electronics, vol. 9, no.3, May 1994, pp.263-268.

3. Janko Nastran, Rafael Cajhen, MatijaSeliger, and PeterJereb, Active Power Filter for Nonlinear AC Loads, IEEETrans. Power Electronics, vol.9, no.1, Jan. 1994, pp. 92-96.

4. E. Destobbeleer and L.Protin, On the Detection of LoadActive Currents for Active Filter Control, IEEE Trans.Power Electronics, vol. 11, no.6, Nov. 1996, pp. 768-775.

5. Mauricio Aredes, Jorgen Hafner, and Klemens Hermann,Three-Phase Four-Wire Shunt Active Filter ControlStrategies, IEEE Trans. Power Electronics, vol.12, no.2,Mar. 1997, pp. 311-318.

6. Hideaki Fujita and Hirofumi Akagi, the Unified PowerQuality Conditioner: The Integration of Series- andShunt- Active Filters, IEEE Tran. Power Electronics,vol. 13, no.2, Mar. 1998, pp.315-322.

7. Fang ZhengPeng, George W. Ott Jr., and Donald J.Adams, "Harmonic and Reactive Power Compensation Basedon the Generalized Instantaneous Reactive PowerTheory for Three-Phase Four-Wire Systems, IEEETrans,Power Electronics, vol.13, no.6, Nov. 1998,pp. 1174-1181.

8. M Hosseinpour, A Yazdian, M Hohamadian, J Kazempour, "Desing andSimulation of UPQC to Improve Power Quality and Transfer Wind Energy toGrid", Jour of Applied Sciences, 2008, vol. 8(21), pp. 3770 378.

9. I. Axente, J. N. Ganesh, M. Basu, M. F. Conlon, and K. Gaughan, “A 12-kVA DSP-controlled laboratory prototype UPQC capable of mitigating unbalance in source voltage and load current," IEEE Trans. Power Electron., vol. 25, no. 6, pp. 1471-1479, Jun. 2010.

10.M. Yun, W. Lee, I. Suh, and D. Hyun, "A new control scheme of unified power quality compensator-Q with minimum power injection," in Proc. IEEE Ind. Electron. Soc. (IECON), Nov. 2-6,, 2004, pp. 51-56.

11. Nabae and T. Tanaka, "A new definition of instantaneous active reactive current and power based on instantaneous space vectors on polar coordinates in three-phase circuits," presented at the IEEE/PES Winter Meeting, Paper 96 WM 227-9 PWRD, 1996.

\section{AUTHORS PROFILE}

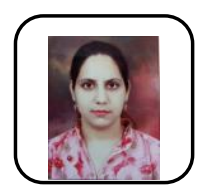

Sandeep Kaur was born on 06-07-1982,

She Received a Bachelor's degree in Electrical Engineering (2004) from Punjab Technical University, Jalandhar, India and received a Master's Degree in Power System (2008) from Punjab Technical University with distinction. Presently she is pursuing P.h.D in Optimization of Power System and Transient Stability Analysis using Facts Controller from I.K. Gujral Punjab Technical University, Jalandhar, India. She is working as Assistant Professor Department of Electrical Engineering in Chandigarh University, Gharuan, Mohali, Punjab for the last 8 years. Her Research interest includes Power System, Simulation, Control System and Optimization Techniques.

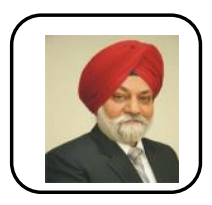

Dr. Raja Singh Khela passed AMIE section A \& B from Institute of Engineers, Kolkata. He did his Master's Degree in Electrical Engineering from Punjab University Chandigarh with distinction. He did his PhD from I.K. Gujral Punjab Technical University, Jalandhar, India in 2010. His topic was Performance Evaluation of Self Excited Induction Generator using Artificial Neutral Network. His Research interest includes Electrical Machines. He is presently working as Director Prinicipal Doaba Group of Colleges Kharar, Punjab, India. 